Keywords: abuse; children; displaced; elderly; missing; Sri Lanka; survival; tsunami

Prebosp Disust Med 2005;20(3):s125-s126

Implementation of an Emergency Measles CampaignAceh Province, Indonesia, January-March 2005

\section{M.B. Brennan}

Center for Disease Control and Prevention, Atlanta, Georgia USA

Introduction: Following the tsunami, there were concerns about the potential for a large measles outbreak in Aceh province, Indonesia. Reasons for the concern were low routine measles vaccine coverage (estimated at $50 \%$ ), population movement, and overcrowding in camps for displaced persons. There also were concerns about access to good case management for the complications of measles.

Methods: The Indonesian Ministry of Health, assisted by the United Nations and non-governmental organization partners, targeted all children in Aceh province aged six months to 15 years to receive a measles vaccine, along with a supplementary dose of Vitamin A. Adjustments were made for missing, dead, and displaced persons when estimating the target population.

Results: The campaign targeted the entire Aceh province. However, priority was given to its capital, Banda Aceh, and three other highly-affected districts: (1) Aceh Besar; (2) Aceh Baret; and (3) Aceh Jaya. The campaign was completed in the first two locations with coverage of $70 \%$ and 94\% in Banda Aceh and Aceh Besar, respectively. The campaign still is in process in the other two districts where heavily damaged infrastructure, loss of local health personnel, and lack of security continue to affect campaign progress.

Keywords: Aceh province; children; campaign; Indonesia; measles; Ministry of Health; vaccination

Prehosp Disast Med 2005;20(3):s126

Post-Tsunami Health Interventions-Support Available from the Cochrane Collaboration and Priorities for Further Systematic Reviews in the Disaster Setting

M. Clarke

Cochrane Collaboration, Oxford, United Kingdom

\section{Theme 13: Disaster Planning \\ Chair: Mauricio Lynn}

Comparison of the Disaster Management Frameworks of the US and the UK: Similarities and Differences

K. Quresbi, ${ }^{1}$ R. Gershon ${ }^{2}$

1. Adelphi University, Garden City, New York USA

2. Columbia University, New York, New York USA

The geopolitical status of the world today intensifies the likelihood that disasters will increase in terms of numbers, type, and complexity. To this end, both the United States (US) and the United Kingdom (UK) have developed disaster management frameworks for the purpose of achieving command, control, and coordination. In the US, it is referred to as the Incident Command System, while in the
UK it is referred to as the Combined Response (or sometimes the Gold, Silver, and Bronze System). Since many disaster events involve response from more than one nation, it is likely that there will be many instances where the US and the UK response teams will work side by side.

The purpose of this presentation is to compare and contrast the two disaster management frameworks, illustrating how they are similar and how they differ. Understanding how partner nations organize response operations is likely to facilitate international coordination and cooperation, and perhaps ultimately assist with the devclopment of a universal standard.

Keywords: Combined Response; disaster management; frameworks; incident command system; preparedness; United Kingdom; United States

Prebosp Disast Med 2005;20(3):s126

Assessment Report on the Amendment of Disaster Medical Services in Japan - What Has Been Changed during the Last 10 Years after the Great HanshinAwaji Earthquake?

Takashi Ukai

Hyogo Emergency Medical Center, Japan

Through the lessons learned from the 1995 Great Hanshin-Awaji Earthquake (GHAE), which struck and destroyed parts of the modernized city of Kobe, The Ministry of Health and Welfare of Japan and the Government of Hyogo Prefecture developed several plans to improve the disaster medical services system. These plans included: (1) development of a widespread emergency and disaster medical information network; (2) designation of core hospitals for use during disasters; (3) education and training of medical personnel on disaster medicine; and (4) collaboration between the fire department and medical experts.

On the 10th anniversary of the GHAE, the Hyogo Prefecture Government organized a committee for the assessment of the countermeasures taken following the earthquake. This presentation deals with the assessment report that was surveyed by the author in 2004 in Hyogo Prefecture. As to the area-wide emergency and disaster medical information system, almost all of the hospitals have been equipped with laptop computers that will be used exclusively for this system. However, most of the hospitals could not use this information system during multicasualty incidents and the earthquake in Nigata in October 2004. Reasons for the low usage rate were investigated.

About 500 hospitals in Japan and 15 in Hyogo Prefecture are designated as disaster core hospitals. They are expected to play leading role in accepting patients in the disaster-affected area, and, if necessary, transfer those patients to the hospitals in the non-affected areas. The preparedness for disasters and capabilities of each of these hospitals were investigated and it revealed that there are many differences between the disaster core hospitals.

Training and education on disaster medicine was minimal before the GHAE, and, if any was provided, it was 